\title{
IMPLEMENTASI KURIKULUM 2013 DI SEKOLAH INKLUSI SEKOLAH DASAR INTERNATIONAL ISLAMIC SCHOOL (INTIS) YOGYAKARTA
}

\author{
Nuniek Rahmatika ${ }^{1}$, Dani Ratrianasari ${ }^{2}$, Hendro Widodo ${ }^{3}$ \\ Manajemen Pendidikan Universitas Ahmad Dahlan Yogyakarta
}

\begin{abstract}
UNESCO established that educational for all. It means that all students are entitled to what he aspired, and without discriminatio. This study aims to find out how the 2013 curriculum can be implemented in inclusive schools. This study uses qualitative methods that aim to obtain a comprehensive and in-depth picture of the issue or phenomenon in inclusive schools, interview, observation and documentation. The subjects of the study were the deputy headmaster of the curriculum section, the inclusion coordinator, the homeroom teacher and the special assistant teacher. The results showed that: 1) The implementation of the 2013 curriculum in inclusive schools began in planning, making lesson plans and Syllabi created together with a special assistant teacher. the preparation of lesson plans and syllabi carried out in accordance with the assessment results based on what psychologists needed by the student. 2) Differences and similarities curriculum 2013 on special needs students. based on this, the lesson plan is still no difference and separation between students with disabilities and regular students. The difference lies in the delivery of the method carried out by the special assistant teacher. 3) The evaluation was applied to the 2013 curriculum for students with special needs do report progress of students with disabilities in collaboration with special assistant teachers. Teacher assistant will analyze the changes that occur in students during the teaching and learning process.
\end{abstract}

Key word: Curriculum 2013, Inclusive schools

\begin{abstract}
Abstrak: UNESCO mecetuskan bahwa educational for all atau pendidikan untuk semua atau pendidikan disemua kalangan yang berarti bahwa semua siswa berhak mendapatkan apa yang dicita-citakan, dan tanpa diskriminasi. Penelitian ini bertujuan untuk mengetahui bagaimana kurikulum 2013 dapat diimplementasikan di sekolah inklusi. Penelitian ini menggunakan metode kualitatif yang bertujuan untuk memperoleh gambaran secara menyeluruh dan mendalam mengenai isu atau fenomena di sekolah inklusi. Wawancara, observasi dan dokumentasi. Subjek penelitian yaitu wakil kepala sekolah bagian kurikulum, koordinator inklusi, wali kelas dan guru pendamping khusus. Hasil penelitian menunjukkan bahwa: 1) Penerapan kurikulum 2013 di sekolah inklusi, dimulai pada perencanaan, pembuatan RPP dan silabus dibuat bersama-sama guru pendamping khusus. penyususnan RPP dan silabus dilakukan sesuai dengan hasil assessmen psikolog berdasarkan apa yang dibutuhkan oleh siswa berkebutuhan. 2) Perbedaan dan kesamaan kurikulum 2013 pada siswa berkebutuhan khusus. berdasarkan hal tersebut, dalam RPP masih belum ada perbedaan dan pemisahan antara siswa berkebutuhan dan siswa reguler. Perbedaan tersebut terletak pada penyampaian metode yang dilakukan oleh guru pendamping khusus. 3) Evaluasi yang diterapkan pada kurikulum 2013 untuk siswa berkebutuhan khusus dengan melakukan laporan perkembangan siswa berkebutuhan bekerjasama dengan guru pendamping khusus. Guru pendamping akan menganalisis perubahan-perubahan yang terjadi pada siswa selama proses belajar mengajar berlangsung. Kata Kunci: Kurikulum 2013, sekolah inklusi.
\end{abstract}

\footnotetext{
'Universitas Ahmad Dahlan Yogyakarta, Email: nuniek国uad.ac.id

${ }^{2}$ Universitas Ahmad Dahlan Yogyakarta, Email: ratri国uad.ac.id

${ }^{3}$ Universitas Ahmad Dahlan Yogyakarta, Email: hendra回uad.ac.id
} 


\section{PENDAHULUAN}

Tantangan layanan pendidikan saat ini adalah menyesuaiakan kurikulum pendidikan dengan kebutuhan pesertadidik yang semakin kompleks, hal ini perlunya pemerintah untuk meningkatkan kualitas pendidikan. Berprinsip pada pendidikan untuk semua, kurikulum menekankan pada pelayanan dalam proses pembelajaran yang baik dan mampu mewadahi seluruh siswa tanpa diskriminasi. Menurut (Aslan, 2017, hlm. 1) mengatakan bahwa sejak kurikulum dipakai dalam dunia pendidikan yang intinya dapat membentuk perilaku anak didik, sehingga kurikulum selalu terkait dengan pendidikan pada tingkat Pra sekolah, dasar, mengengah maupun tinggi.

Sebagaimana mestinya kurikulum memiliki kedudukan yang sangat penting. Kurikulum merupakan suatu proses bagaimana untuk memberikan pengalaman belajar kepada siswa dan bagaimana sekolah membentuk budaya yang positif dan lingkungan yang nyaman serta dapat diterima oleh warga sekolah. Selain itu menurut Hamalik (2016, hlm. 11-12) peran kurikulum adalah peranan konservatif. Salah satu tanggung jawab kurikulum adalah mentransmisikan dan menafsirkan sosial generasi muda. Dengan demikian, sekolah sebagai suatu lembaga sosial dapat mempengaruhi dan membina tingkah laku siswa sesuai dengan berbagai nilai sosial yang ada dalam masyarakat, sejalan dengan peranan pendidikan sebagai proses sosial. Maka sudah menjadi tugas kurikulum untuk menciptakan lingkungan yang nyata dalam proses sosial di lingkungan sekolah.

Kurikulum 2013 dimaksudkan untuk mengembangkan dari kurikulum KTSP (Kurikulum Tingkat Satuan Pendidikan). Kurikulum 2013 ini lebih terlihat perbedaan pada mata pelajaran tematik yang meliputi mata pelajaran IPA, IPS, PPKN, Seni Budaya dan bahasa Indonesia diikat pada satu mata pelajaran yang disebut dengan tematik. Namun pada kurikulum KTSP dipisahkan dan menjadi masing-masing mata pelajaran. Namun pada kurikulum 2013 ini terdapat 4 kompetensi inti di dalam KTSP meliputi: kompetensi dasar, diantaranya; Ki (I) kompetensi inti berkaitan pada habluminallah atau hubungan spiritual, $\mathrm{Ki}$ (II) kompetensi inti berkaitan pada habluminannas atau hubungan sosial, $\mathrm{Ki}$ (III) kompetensi inti berkaitan pada aspek pengetahuan dan Ki (IV) kompetensi inti pada aspek keterampilan. Kompetesi ini yang nantinya akan dipadukan di dalam rencana perangkat pembelajaran yang disiapkan oleh guru mata pelajaran.

Untuk siswa normal maupun siswa berkebutuhan pasti memiliki kesulitan dalam pembelajaran, mereka perlu mendapatkan pembelajaran yang baik yang sesuai dengan kebutuhan mereka agar dapat menjalankan tugas-tugas secara maksimal. Namun untuk siswa berkebutuhan tentunya memiliki perbedaan dalam assesmen, metode pembelajaran serta perlakuannya. Oleh karena itu, dalam kurikulum 2013 yang mengedepankan pada kemandirian siswa serta keaktifan siswa di dalam kelas selama proses belajar mengajar, bagaimana memberikan perlakukan yang baik. Sehingga anak yang normal maupun berkebutuhan tetap memiliki tujuan dalam pembelajaran.

Istilah sekolah inklusi sudah kita kenal sejak diberlakukannya kemendiknas No.70 tahun 2009 tentang Pendidikan Inklusif bagi Peserta Didik yang Memiliki Kelainan dan Memiliki Potensi Kecerdasan dan/Bakat Istimewa. Pada pasal 1 dijelaskan bahwa pendidikan inklusif adalah sistem penyelenggaraan pendidikan yang memberikan kesempatan kepada semua peserta didik yang memiliki kelainan dan memiliki potensi kecerdasan dan/atau bakat istimewa untuk mengikuti pendidikan atau pembelajaran dalam satu lingkungan pendidikan secara bersamasama dengan peserta didik pada umumnya. Menurut Salim (2010, hlm. 21) pendidikan inklusif pada dasarnya adalah pendidikan yang mengikutsertakan anak-anak yang memiliki kebutuhan khusus (ABK/penyandang cacat) untuk belajar 
bersama-sama dengan anak lainya sebayanya di sekolah umum.

Dalam hal ini sejauh mana implementasi kurikulum 2013 dapat diberlakukan di dalam sekolah inklusif. Menurut Kamaliah (2018, hlm. 107-108) mulai awal tahun 2014 pemerintah mengambil kebijakan untuk setiap sekolah agar mampu mengimplementasikan kurikulum 2013 dalam proses pembelajaran. Kebijakan tersebut tidak hanya ditujukan pada sekolah reguler, pada sekolah inklusif pun diharapkan dapat mengimplementasikan kurikulum 2013 dalam proses pembelajaran baik untuk peserta didik reguler maupun peserta didik berkebutuhan khusus. Kurikulum dikembangkan sesuai dengan tahap perkembangan anak, kebutuhan pembangunan nasional, serta perkembangan ilmu pengetahuan dan teknologi, sesuai dengan jenis dan jenjang masing-masing satuan pendidikan. Hal tersebut dimaksudkan bahwa siswa berkebutuhan khusus tetap perlu diberikan layanan yang tepat sesuai dengan kebutuhannya dan tanpa diskriminasi. Menurut Anjarsari (2018, hlm. 92) selama ini anak berkubutuhan khusus mengikuti pendidikan yang sesuai dengan kelainannya. Secara tidak langsung hal ini telah mendeskriminasi anak berkabutuhan khusus, akibatnya menghambat proses saling mengenal antara anak reguler dengan anak berkebutuhan khusus. Dampaknya anak berkebutuhan khusus menjadi tersingkirkan dalam berinteraksi dengan masyarakat. Bersamaan dengan berkembangnya tuntutan anak berkebutuhan khusus dalam menyuarakan hak-haknya, serta berdasarkan pemenuhan hak atas pendidikan bagi seluruh anak di Indonesia maka muncullah konsep pendidikan inklusi.

Dengan adanya perhatian khusus, maka implementasi pada kurikulum khusus untuk ABK adanya modifikasi pada silabus ataupun RPP yang akan direncanakan. Tentu hal tersebut tidaklah mudah, perlu adanya sinergisitas antara guru mata pelajaran dan guru pendamping khusus. Berdasarkan hasil wawancara terhadap koordinator inklusi SD INTIS Yogyakarta, diketahui bahwa SD INTIS Yogyakarta telah melaksanakan kurikulum 2013 dalam proses pembelajaran di sekolah. Namun menurut wakil kepala sekolah bagian kurikulum mengatakan bahwa kurikulum 2013 ini baru diterapkan tiga tahun terakhir oleh siswa kelas 1 sampai dengan kelas 5 . Untuk kelas 6 masih menggunakan kurikulum KTSP, baru tahun ini akan diterapkan kurikulum 2013 di kelas 6.

Berdasarkan hal tersebut rumusan masalah dalam penelitian ini meliputi; a) Bagaimana penerapan kurikulum 2013 pada sekolah inklusi? b)apakah ada perbedaan dan kesamaan kurikulum 2013 terhadap siswa berkebutuhan khusus? c)Bagaimana proses evaluasi dalam kurikulum yang telah terlaksana terhadap siswa berkebutuhan khusus?

Berdasarkan uraian tersebut penelitian ini bertujuan untuk mengambarkan atau mendeskripsikan tentang implementasi kurikulum 2013 di sekolah inklusi SD International Islamic School Yogyakarta.

Penelitian ini diharapkan berguna bagi pengembangan pendidikan inklusif di SD INTIS Yogyakart, antara lain adalah:

1. Bagi sekolah diharapakam mampu mempertahankan mutu sekolah inklusif dan semkain memberikan pelayanan yang berkaitan dengan siswa berkebutuhan khusus.

2. Sebagai bahan kajian yang berkaitan dalam kurikulum di sekolah inklusif baik secara umum maupun khusus.

3. Dapat memberikan edukasi bagi masyarakat dan orang tua khsusunya untuk memberikan arahan dan tempat pendidikan yang layak bagi anak berkebutuhan khusus.

\section{METODOLOGI PENELITIAN}

Penelitian ini menggunakan metode penelitian deskriptif kualitatif. Teknik pengumpulan data dilakukan dengan wawancara, observasi dan dokumentasi. 
Data dianalisis melalui reduksi data, model data dan penarikan kesimpulan. Pengambilan data dengan wawancara, observasi dan dokumentasi yang dilakukan di SD INTIS Yogyakarta. Teknik keabsahan data yang digunakan dalam penelitian ini adalah triangulasi data. Subjek data yang mana sebagai informan dalam penelitian ini yang terdiri dari:

\begin{tabular}{|c|c|}
\hline INISIAL & SUBJEK \\
\hline I.m & $\begin{array}{c}\text { Wakil kepala sekolah } \\
\text { bagian kurikulum }\end{array}$ \\
\hline F.m & Koordinator inklusi \\
\hline L.n & Wali kelas L.5 \\
\hline R.h & $\begin{array}{c}\text { Guru pendamping } \\
\text { khusus }\end{array}$ \\
\hline
\end{tabular}

\section{Desain Penelitian}

Dalam penelitian ini, teknik pengumpulan data yang digunakan adalah:

a. Wawancara

Dalam penelitian ini, wawancara akan dilakukan kepada beberapa pihak, antara lain wakil kepala bagian kurikulum, guru pendamping khusus, dan guru kelas/wali kelas.

b. Observasi

Penelitian ini dalam observasi meliputi, observasi dalam proses pembelajaran di kelas.

c. Dokumentasi

Pada penelitian ini dokumentasi dilakukan sebagai data penunjang untuk memperkuat hasil penelitian. Dimana dokumen tersebut bisa berbentuk tulisan.

\section{HASIL PENELITIAN}

Hasil penelitian berisi deskripsi hasil analisis data penelitian yang sudah terorganisasi dengan baik. Data penelitian disajikan secara informatif, komunikatif, dan relevan dengan masalah dan tujuan penelitian. Dalam bab ini, hasil penelitian berupa deskripsi analisis yang disajikan dalam uraian bersifat kualitatif yaitu data yang digambarkan dengan kata-kata atau kalimat. Adapun hasil penelitian ini merupakan paparan data hasil penelitian yang berhasil digali melalui wawancara, observasi, serta dokumentasi terhadap peristiwa dan hasil kajian terhadap beberapa dokumen yang dipilih oleh peneliti.

Informan dalam penelitian ini merupakan pihak yang berhubungan langsung dengan implementasi kurikulum 2013 di SD INTIS yang nama terangnya diinisialkan untuk menjaga privasi informan dalam publikasi penelitian.

Menurut F.m sebagai koordinator inklusi mengatakan bahwa pendidikan inklusi merupakan model penyelenggaraan pendidikan bagi anak berkebutuhan khusus. Menurut Herawati dalam artikelnya model yang lain diantaranya meliputi:

a) Sekolah regresi meliputi sekolah yang memisahkan anak berkerbutuhan khusus dari sistem persekolahan reguler. Di Indonesia bentuk sekolah segresi ini berupa satuan pendidikan khusus atau Sekolah Luar Biasa sesuai dengan jenis kelainan peserta didik. Seperti SLB/ A untuk anak Tuna netra, SLB/B untuk anak tuna rungu, SLB/E untuk anak tuna laras dan lain-lain. Sistem pendidikan yang digunakan terpisah sama sekali dari sistem pendidikan di sekolah reguler, baik kurikulum, tenaga pendidik dan kependidikan, sarana prasarana, sampai pada sistem pembelajaran dan evaluasinya.

b) Sekolah terpadu adalah sekolah yang memberikan kesempatan kepada peserta didik berkebutuhan khusus untuk mengikuti pendidikan di sekolah reguler tanpa adanya perlakuan khusus yang disesuaikan dengan kebutuhan individual anak. Sekolah tetap menggunakan kurikulum, sarana prasarana, tenaga pendidik dan kependidikan, serta sistem pembelajaran reguler untuk semua peserta didik. Jika ada peserta didik tertentu mengalami kesulitan dalam 
mengikuti pendidikan, maka konsekuensinya peserta didik itu sendiri yang harus menyesuaikan dengan sistem yang dituntut di sekolah reguler. Dengan kata lain pendidikan terpadu menuntut anak yang harus menyesuaikan dengan sistem yang dipersyaratkan sekolah reguler.

c) Sekolah inklusif merupakan perkembangan baru dari pendidikan terpadu. Pada sekolah inklusif setiap anak sesuai dengan kebutuhan khususnya, semua diusahakan dapat dilayani secara optimal dengan melakukan berbagai modifikasi dan/atau penyesuaian, mulai dari kurikulum, sarana prasarana, tenaga pendidik dan kependidikan, sistem pembelajaran sampai pada sistem penilaiannya. Dengan kata lain pendidikan inklusif mensyaratkan pihak sekolah yang harus menyesuaikan dengan tuntutan kebutuhan individu peserta didik, bukan peserta didik yang menyesuaikan dengan sistem persekolahan.

Pernyataan tersebut jelas berbeda antara sekolah regresi, terpadu dan sekolah inklusi. Dalam hal ini pendidikan inklusi memberikan kesempatan dan memanusiakan-manusia tanpa melihat latar belakang, siswa diberikan kesempatan untuk berinteraksi dengan bebas dan mengikuti pelajaran dan mendapatkan teman seperti siswa-siswa yang lainnya. Herawati juga menjelaskan bahwa dalam manajerial sekolah inklusif bahwasannya sekolah reguler harus siap mengelola kelas yang heterogen dengan menerapkan kurikulum dan pembelajaran yang bersifat individual. Menurut Aslan (2017, hlm. 1) mengatakan bahwa anak berkebutuhan khusus dan anak normal, tingkat kurikulumnya sama saja, tapi disisi lain perbedaanya pasti ada, yakni pada evaluasinya.

\section{Pembahasan}

Sekolah SD INTIS Yogyakarta yang mana telah dilaksanakan observasi bahwa terlihat memang adanya kelas heterogen. Dimulai dari kelas L.1 sampai pada L.6 atau (Level 1-level 6), semua kelas terisi dengan siswa-siswi berkebutuhan dan siswa-siswi yang reguler (normal). Menurut Tiara (2019, hlm. 24) Sikap sosial merupakan ekspresi atau tindakan seseorang dalam menyikapi sesuatu dalam kehidupan sosial. Kelas merupakan tempat dimana siswa berinteraksi dengan lingkungan sekitarnya. Di dalam kelas yang heterogen tersebut agar tercipta budaya dan pengalaman belajar oleh siswa tentang bagaimana sikap menghormati, mengasihi dan menyayangi sesama teman baik yang berkebutuhan ataupun siswa dalam kategori normal. Menurut paparan F.m selaku koordinator inklusi mengatakan bahwa, adanya hubungan yang baik antara orang tua, educator dan guru pendamping untuk bekerjasama agar terciptanya rasa dukungan yang akan berpengaruh pada perkembangan psikologis anak.

Hasil wawancara yang dilakukan kepada I.m selaku bagian kurikulum mengatakan bahwa dalam kurikulum 2013 sangat berdampak positif pada siswa reguler maupun berkebutuhan. Sistem pendidikan di Indonesia telah mengalami beberapa kali perbaikan kurikulum. Hal ini tercermin dengan adanya perubahan kurikulum, mulai dari kurikulum 1947, 1952, 1964, 1968, 1975, 1984, 1994, 2004, 2006, dan 2013. Perbaikan kurikulum merupakan bagian penting dalam pengembangan kurikulum yang bertujuan untuk meningkatkan kualitas pendidikan sesuai dengan tujuan pendidikan nasional. Menurut Fadlillah (2014, hlm. 31). Kurikulm 2013 sangat detail dalam kompetensi inti, dan sangat bagus dalam pengembangan karakter siswa. Menurut Mahmuddah (2017, hlm. 261) Pengembangan karakter dilakukan dengan menanamkan nilai-nilai etika dasar (core ethical values) sebagai basis bagi karakter 
yang baik. Tujuannya adalah agar peserta didik mempunyai karakter yang baik. Indikator karakter yang baik terdiri dari pemahaman dan kepedulian pada nilai-nilai etika dasar serta tindakan atas dasar inti nilai etika atau etika yang murni. Selain itu tujuan lain dalam karakter siswa dalam kurikulum 2013 sangat berpengaruh pada siswa berkebutuhan khusus. Peran keluarga, masyarakat dalam membangun karakter mendapatkan dampak yang signifikan dalam memelihara dan mengasuh siswa berkebutuhan. Kesiapan tersebut merupakan kunci pengobatan untuk menyediakan lingkungan yang ramah.

Dalam K.I 2 yang merupakan hubungan sosial, menerapkan karakter sopan santun pada siswa baik reguler maupun non reguler. Namun dalam kurikulum 2013 guru kesulitan dalam K.I 3 dan K.4 yang merupakan aspek ilmu pengetahuan dan aspek keterampilan. Pemaparan I.m tersebut mengatakan bahwa K.i 1 dan K.2 ada form tersendiri, form tersebut digunakan sebagai catatan harian dan akan dilaporkan pada akhir semester. Berbeda dengan K.I 3 dan K.4 guru perlu memperhatikan secara detail sebagai evaluasi proses ketika kegiatan belajar mengajar berlangsung. Kelemahannya pada form tersebut guru-guru mengisi pada saat waktu luang, dan bahkan form tersebut ada yang tidak diisi sama sekali.

Hasil wawancara dengan L.n bahwasannya untuk siswa berkebutuhan ada grade tersendiri. Untuk menentukan itu dari pihak sekolah dan bekerjasama dengan psikolog serta orang tua siswa diberikan assessmen untuk mengetahui apakah siswa berkebutuhan butuh untuk pendampingan dari guru pendamping khsus, ataukah siswa berkebutuhan memang sudah mandiri untuk mengikuti pembelajaran di kelas.

Berdasarkan studi dokumentasi juga didapatkan bentuk RPP dalam kurikulum 2013 belum adanya perbedaan yang signifikan antara siswa berkebutuhan dan siswa reguler. Di SD INTIS Yogyakarta menurut F.m sebagai koordinator inklusi juga mengatakan bahwasannya silabus ataupun RPP untuk siswa berkebutuhan seharusnya memiliki perbedaan pada indicator, learning goals dan learning methods yang mana disesuaikan pada kebutuhan siswa yang berkebutuhan. Namun karena kesibukan guru untuk mengurusi hal yang lainnya, tidak semua guru merubah dan membedakan RPP siswa reguler maupun siswa berkebutuhan. Sebab hal lain, terkait metode belajar diserahkan kepada guru pendamping khusus. Selain pada tugas guru pendamping khusus untuk ikut membantu pada proses perencanaan pembelajaran. Selanjutnya pada tahap evaluasi pada siswa berkebutuhan khusus dan akan dijadikan laporan akhir semester, guru pendamping khusus memberikan laporan tentang perkembangan siswa yang diampu atau yang diberikan pendampingan khusus. Namun dengan kendala situasi yang ada, guru mata pelajaran ataupun wali kelas memiliki kesibukan maka terkadang guru membuat RPP disamakan indikator keberhasilan siswa reguler dan siswa berkebutuhan.

Menurut Mumpuniarti (2007, hlm. 77) idealnya semua anak berkebutuhan khusus dilayani program pembelajaran individual (PPI). Berdasarkan hasil wawancara dengan R.h sebagai guru pendamping khusus mengatakan bahwa, guru pendamping khusus dalam proses pembelajaran dan pentransferan suatu pelajaran untuk siswa berkebutuhan mengalami kesulitan dalam mata pelajaran tematik, yang mana mata pelajaran tematik merupakan satu kesatuan dari mata pelajaran IPA, IPS, PPKN, Bahasa Indonesia dan Seni Budaya. Dalam kurikulum 2013 menekankan pada siswa untuk dapat mandiri dan menerima pembelajaran dengan inovatif, namun untuk guru pendamping sendiri hanya dapat menjelaskan secara terbatas untuk siswa berkebutuhan. Guru pendamping khusus mengatakan memang dalam metode pembelajaran sangat berbeda untuk siswa berkebutuhan itu sendiri. Misal siswa yang memiliki gangguan pemusatan perhatian 
akan berbeda metode atau cara penyempaian yang diberikan kepada siswa yang memiliki diseleksia. Hal terpenting adalah kurikulum apapun yang digunakan perlunya guru yang mengajar anak berkebutuhan harus memiliki kejelian dan kepekaan terhadap anak.

\section{KESIMPULAN}

Dari hasil pembahasan keseluruhan model di atas dapat di simpulkan bahwa:

1. Penerapan kurikulum 2013 di sekolah inklusi, dimulai pada perencanaan, pembuatan RPP dan silabus dibuat bersama-sama guru pendamping khusus. penyususnan RPP dan silabus dilakukan sesuai dengan hasil assessmen psikolog berdasarkan apa yang dibutuhkan oleh siswa berkebutuhan.

2. Perbedaan dan kesamaan kurikulum 2013 pada siswa berkebutuhan khusus. berdasarkan hal tersebut, dalam RPP masih belum ada perbedaan dan pemisahan antara siswa berkebutuhan dan siswa reguler. Perbedaan tersebut terletak pada penyampaian metode yang dilakukan oleh guru pendamping khusus.

3. Evaluasi yang diterapkan pada kurikulum 2013 untuk siswa berkebutuhan khusus dengan melakukan laporan perkembangan siswa berkebutuhan bekerjasama dengan guru pendamping khusus. Guru pendamping akan menganalisis perubahanperubahan yang terjadi pada siswa selama proses belajar mengajar berlangsung.

\section{DAFTAR PUSTAKA}

Anggun, D. A, dkk. (2018). Penyelenggaraan Pendidikan Inklusi pada Jenjang SD, SMP dan SMA di Kabupaten Sidoarjo. Jurnal Pendidikan Inklusi.

Aslan. (2017). Kurikulum Bagi Anak Berkebutuhan Khusus (ABK). Volume 5 No 2. Jurnal Studi Insania.
Kamaliah, D. (2018). Implementasi Kurikulum 2013 Bagi Peserta Didik Berkebutuhan Khusus di SMK Inklusif Negeri 2 Malang. 2018. Volume 1 Nomor 2. Jurnal Pendidikan Inklusi.

Fadlillah, M. (2014). Implementasi Kurikulum $2013 \quad$ Dalam Pembelajaran SD/MI, SMP/MTS, SMA/MA. Volume 5 No 1. Jurnal Pembangunan Pendidikan.

Hamalik, O. (2016). Dasar-dasar Pengembangan Kurikulum. Bandung : PT Remaja Rosdakarya.

Kemendiknas No 70 tahun 2009 tentang Pendidikan Inklusif bagi Peserta Didik yang Memiliki Kelainan dan Memiliki Potensi Kecerdasan dan/Bakat Istimewa

Mahmuddah , D. E., \& Sukria, H. (2017). Pendidikan Karakter dalam Bimbingan dan Konseling Berorientasi pada Psycological Well Being Siswa. Bimbingan dan Konseling .Volume 1 No 1. Prosiding Seminar Bimbingan dan Konseling

Mumpuniarti. (2007). Pendekatan Pembelajaran Bagi Anak Hambatan Mental. Yogyakarta: Kanwa Publisher.

Salim, A. (2010). Pengembangan Model Modifikasi Kurikulum Sekolah Inklusif Berbasis Kebutuhan Individu Peserta Didik . Volume 16 No 1. Jurnal Pendidikan dan Kebudayaan.

Tiara, S. K. (2019). Analisis Teknik Penilaian Sikap Sosial Siswa dalam Penerapan Kurikulum 2013 di SDN 1 Watulimo. Volume 11 No 1. Jurnal Pendidikan Dasar. 